\title{
A Hazard Model of the Probability of Medical School
}

\section{Dropout in the United Kingdom}

\author{
Wiji Arulampalam ${ }^{*}$, Robin A. Naylor, and Jeremy P. Smith \\ University of Warwick
}

June 2003

Keywords: Medical students, Student dropout (non-completion) probabilities, Multi-level Models, Limited duration model, Survival analysis, Competing risks.

JEL Classification No.: $\quad$ J24, I2, C41

Address for correspondence: Department of Economics, University of Warwick, Coventry, CV4 7AL, UK. Email:,wiji.arulampalam@warwick.ac.uk, robin.naylor@warwick.ac.uk,jeremy.smith@warwick.ac.uk Web-site: http://www.warwick.ac.uk/Economics

${ }^{*}$ Also, IZA, Bonn, Germany.

We are grateful to Norman Ireland, Costas Meghir, Geert Ridder, Jim Walker, seminar participants at IZA, Bonn, at the University of Warwick, and Centre for Health Service Studies. Comments from two anonymous referees and the editor are also gratefully acknowledged. We acknowledge both the USR, as the original depositors, and the UK Data Archive for the use of the data-set SN:3456 Universities' Statistical Record. None of these individuals or organisations bears any responsibility for any of the analysis or interpretations presented in this paper. 


\begin{abstract}
.
From individual-level longitudinal data for two entire cohorts of medical students in UK universities, we use multi-level models to analyse the probability that an individual student will drop out of medical school. We find that academic preparedness - both in terms of previous subjects studied and levels of attainment therein - is the major influence on medical student withdrawal. Additionally, males and more mature students are more likely to withdraw than females or younger students, respectively. We find evidence that the factors influencing the decision to transfer course differ from those affecting the decision to drop out for other reasons.
\end{abstract}




\section{Introduction}

The issue of the determinants of medical student dropout probabilities is important and topical in both the UK and beyond for a variety of reasons. First, there is serious and growing concern in the UK and elsewhere regarding a shortage in the domestic supply of medical doctors. The Third Report of the UK's Medical Workforce Standing Advisory Committee (MWSAC, 1997) observes that there will be a deficit of doctors in Europe early in this century (MWSAC, 1997. p. 30). This has led to Government-supported enquiries into the causes and potential cures for this problem. The most obvious policy initiative is to train more doctors. The MWSAC (1997) report concluded that a substantial increase in medical school intake was required to meet the future workforce needs of the UK National Health Service. In response, the Government allocated 1,129 new medical places, in a three-stage process commencing in 1999. The subsequent NHS Plan 2000 announced the Government's target of a further 1,000 medical places, with the expectation that the majority of the additional student intake will be in place by 2006 . These changes imply that the total medical school intake will have almost doubled over a 10-year period from 1997. As has been highlighted in policy discussions (MWSAC, 1997), an expansion of medical student numbers begs questions regarding both student quality and student retention. This paper attempts to inform our understanding of the latter issue.

A second reason for examining medical student dropout behaviour relates to the UK debate on the desirability of 'widening' access into higher education, in general, and into medical schools in particular. There has been a lively and high-profile debate in the UK concerning the extent of accessibility of medical schools to students regardless of their social or school background (see McManus (1998) and the related discussion). This has led to explicit recommendations to broaden access to undergraduate medical education (Angel and Johnson, 2000). Predicting the likely impact of such policies on retention and progression is 
clearly an important issue. A third reason for analysing medical student withdrawal is related to the debate concerning the extent to which previous educational qualifications affect medical student performance and progression (see, for example, McManus et al., 1999). Additionally, Arulampalam, et al., (2003) analyse the determinants of first year dropouts over the period 1980-1992. An issue here concerns whether it should be compulsory for medical students to have studied science subjects prior to enrolment.

The rest of this paper is organised as follows. Section 2 presents a discussion of the institutional and policy contexts, which provide the backdrop to our analysis of data on UK medical students. Section 3 describes the data set. Section 4 presents the econometric model together with a discussion of relevant issues regarding our model estimation procedure. We

note that our study is the first in the literature to apply a hazard model to the analysis of undergraduate student withdrawal. We also observe that no previous analysis of medical student withdrawal in the UK has exploited data on full cohorts of medical students. In Section 5, we present estimates of the determinants of dropout probabilities based on a single-risk hazard model. The basic dropout-probability model presented in Sections 4 and 5 is then extended in Section 6 to a more detailed analysis of the underlying reasons for withdrawal through the application of a 'competing risks' framework. Finally, Section 7 closes the paper with conclusions and further remarks.

\section{Institutional context and public policy}

Labour economics focuses chiefly on the analysis of decentralised labour markets in which equilibrium outcomes emerge from the interplay of the forces of supply and demand, where these forces are governed significantly by the price of labour. In important respects, however, the labour market for medical practitioners in the UK is better described by a planning model than by a model of a purely decentralised market. Primarily, this is because of the nature of the necessary regulation in the market. In the UK, doctors are trained within medical schools 
funded and regulated by the government. In large part, this arrangement follows from the still predominantly public nature of medical provision under the auspices of the National Health Service. Currently in the UK, as in many other countries, there are major concerns regarding a growing shortage of medical doctors. The UK solution to this problem is perceived as requiring more efficient planning of the medical workforce. This is a very different approach from that recently recommended from an analysis of the shortage of postgraduate students of Economics in the UK (see Machin and Oswald, 2000). In that case, the problem was attributed largely to a distortion in the relative price of labour. The Third Report of the Medical Workforce Standing Advisory Committee (MWSAC, 1997) to the Secretary of State for Health bears testimony to this reliance on a planning approach and also makes plain how such an approach - to be effective and efficient - demands a wealth of detailed data and appropriate accompanying analysis. In part, the nature of this information requirement is a consequence of the lengthy training period and the time lags between forecasting future supply and demand and the subsequent 'production' of the medical workforce. Uncertainties in demographic trends and in the evolution of medical technologies compound the difficulties associated with forecasting and planning.

The Third Report of the MWSAC proposed a number of measures to prevent what it describes as 'the current significant imbalance' between demand and the domestic supply of doctors from becoming 'increasingly severe'. A main conclusion of the Report was that there should be a substantial increase in medical student intake (about 1,000 per annum) together with policies to ensure 'minimised levels of wastage from such courses, thereby increasing the proportion of entrants that qualify as doctors.' Of course, a significant incentive to reduce wastage rates lies in the high cost associated with medical training. There is no consensus figure on the full cost of a medical training - partly because the costs vary across institutions and are borne by a variety of parties - but a figure of around $£ 50,000$ per annum is often 
quoted. One element of the proposed package of measures to address the issue of minimising wastage concerns changes in selection procedures of candidates for medical schools in order to 'obtain graduates with a wider range of skills and interests.' The related issue of selection and admission of students into medical schools in the UK has itself been the recent focus of significant debate.

As the MWSAC report has emphasised, the development of strategies to minimise the medical student dropout rate should be conducted in the light of analysis of the determinants of completion and withdrawal behaviour by medical students. This has been rendered difficult in the UK by a lack of reliable data and analysis. The MWSAC Report acknowledges that there is significant uncertainty regarding estimates of medical school qualification rates. Estimates are typically based on the difference between the annual intake of students at each medical school and the number qualifying five years later. This is imprecise partly because of variations over time and across institutions in the number of students taking intercalated degrees, for example, and hence taking longer to qualify. Thus, it is not surprising that there is so much variation in the estimated drop-out rates, which fluctuated (with no systematic trend) between $8 \%$ and 14\% during the period 1986/7 and 1991/2 (see MWSAC, $3^{\text {rd }}$ Report, p. 65). So severe is the information problem regarding the drop-out rate that the Third Report of the MWSAC acknowledges that all its analysis and recommendations rest on an estimated student wastage rate which is itself based on 'some anecdotal evidence that drop out is falling' (p. 25). One of the eight recommendations of the Report called for more information and research into medical school wastage rates, inter alia.

In the absence of reliable data on medical school dropout rates, different studies have produced widely varying estimates of the average national rate. Parkhouse (1996) uses University Statistical Record (USR) and Higher Education Funding Council (HEFCE) data on medical school intake and numbers qualifying five years later and estimates an average 
UK drop-out rate of between 11.7\% and 14.1\%. McManus (1996) disputes these figures and cites survey evidence that the rate is around $7 \%$ or $8 \%$, with about half of the students who drop out doing so for non-academic reasons.

Previous data and accompanying analysis have been based, typically, either on aggregated (medical school-level) official data from the USR or HEFCE or on follow-up surveys of particular sub-samples of medical students. This mirrors the situation regarding the analysis of all UK university students across all subject areas. Very recently, however, (anonymised) individual student-level administrative data for full population cohorts of students have become available to researchers for the period 1972-1993. These data contain rich information not only on the academic characteristics of students in UK universities (their courses, institutional affiliation, performance, reasons for leaving, inter alia) but also on their personal, social, and prior educational characteristics. These data offer the prospect of much more precise estimates of dropout rates and of detailed analytical investigation of the factors associated with dropout behaviour. This is of clear interest and relevance to the issue of examining the impact of changing selection procedures on medical students' dropout probabilities (see, for example, Angel and Johnson, 2000). Given the public policy importance of the issue, in the current paper we focus exclusively on a detailed analysis of the determinants of the withdrawal probability of UK medical students.

Individual UK student-level data have previously been exploited to analyse academic performance and dropout probabilities of students on 3 or 4-year degree programmes (Smith and Naylor, 2001a, 2001b). These studies have omitted medical students for a variety of reasons, including the fact that medical courses are significantly longer than standard undergraduate programmes and the fact that medical students' characteristics are typically rather different from those of other students. Average A-level attainment, for example, is much higher for medical students, whose average A-level points score was 26 for the cohorts 
considered in this paper, compared to a score of less than 22 points for contemporaneous nonmedical students - a difference of more than two A-level grades. Accordingly, it is appropriate to model medical student behaviour separately from that of other students.

\section{The Data}

All higher education institutions - including all medical schools - in the UK are required annually to deposit comprehensive longitudinal individual student records data with a central government agency. Our dataset is based on these administrative data from the anonymised individual Universities Student Records (USR) for the full populations of undergraduate students leaving university in the UK in one of the academic years 1985-1993. From information on each of these 'leaving cohorts', we have generated a dataset comprising all those full-time students who entered university at the start of the academic year 1985 or 1986 to study for a medical degree and who had either completed their course by the end of July 1993, or had left their medical degree program prior to completion.

The reason for the choice of starting years 1985 and 1986 is based on data considerations. Data availability restricts us to cohorts leaving university no later than 1993. In general, a medical degree in the UK takes five years to complete and the analysis is therefore conducted on students who enrolled for a five-year degree program. Traditionally, the first two years have been classified as pre-clinical and the latter three as clinical parts of the degree. At the end of the second year of the program, those who perform well are given the opportunity to take an extra year in order to complete a Bachelor of Science degree before continuing with their medical degree. If they are successful, these students will then have taken a minimum of six years to complete their original degree. Students are also allowed to retake any failed examinations during their course of studies. In order to proceed to the next year of the degree program, the student is required to pass the examinations (either at the first attempt or after re-sits). Students who completed their medical degree program in 1993 after 
5 years of study would have first enrolled in 1988. However, if we study only these students, we will fail to observe students taking more than 5 years to complete. For this reason, we prefer to consider students who enrolled no later than 1986 as this gives us a minimum of 7 years over which to observe their withdrawal or completion. In order to increase the size of our dataset, we also include the 1985-starting cohort. The two cohorts will have faced very similar labour market and related conditions. This becomes less true if we take additional earlier cohorts.

In the event of non-completion, an administrative leaving date is recorded along with a university-recorded reason for the student's withdrawal. From this information, we find that among those who registered for a medical degree, course transfers account for around $26 \%$ of all withdrawals, with academic reasons accounting for $36 \%$ and other reasons accounting for $32 \%$. From the point of view of the medical profession, what matters is the simple dichotomy between completion and withdrawal. In our basic model, this distinction forms the basis for our dichotomous dependent variable. In Section 6 of the paper, we also exploit information on the reason for withdrawal within a competing-risks framework.

In this paper, an individual is assumed to have successfully completed if s/he obtains a medical degree by the end of five to seven years (and 8 years for the 1985 cohort) regardless of whether the individual had to re-sit some examinations. Dropout is defined as withdrawal from the medical degree program for whatever reason. All those who are observed to have dropped out of the program after five program years are assumed to have dropped out in the final year of the program. Thus, the standard length of the medical program, which is five years, is used as the duration time in our analysis rather than the actual calendar time taken for completion. Hence, by the end of the fifth year there is assumed to be a forced termination: a successful completion, or a dropout. 
Column 1 of Table 1 provides some information about dropout rates. The 1985 cohort consists of 3,889 students, while the 1986 cohort has 3,900 students. The unconditional noncompletion rate for all students who started a medical degree in either 1985 or 1986 is around $11 \%$. From these two cohorts of medical students, $8.1 \%$ actually dropped out from university altogether (with $2.8 \%$ dropping out of a medical degree due to a change in course). This $8.1 \%$ non-completion rate compares with a value of $8.9 \%$ obtained by Smith and Naylor (2001b) looking at all three and four-year degree courses for students commencing a degree at the start of the academic year in 1989.

Looking at the conditional dropout rates of medical students, we see that as the student progresses through the program, the conditional dropout rate declines quite dramatically. About $50 \%$ of those who do not complete their medical degree leave prior to the start of their second year. This finding is very similar to that found by Smith and Naylor (2001b), where across all students, the equivalent figure was $55 \%$, and is similar to that found in the U.S. by Porter (1990) across all students. The conditional dropout rate in the final year of the program is only $0.37 \%$.

In the UK, the usual age of entry into a university medical school is 18 . Looking at Table 2 we see that $62 \%$ of our sample members are aged 18 or less on entry, with a slightly lower proportion found among the dropouts compared to those who successfully complete. Although our sample contains an approximately equal split of male and female students, males are found to predominate among the dropouts.

In the two cohorts used in the analysis, $94 \%$ of the students were of UK nationality. Fees charged by universities depend on the nationality as well as on some residency conditions. In general, UK students are liable for a UK fee, which is much smaller than the overseas student's fee. In any case, for the cohorts we are analysing in the present paper, all fees facing a UK student were paid for by the student's local education authority. A European 
Union student would be liable for paying the UK level of fee. In the academic year 2002-03, this is just over $£ 1,100$ per annum. The overseas fee varies across universities, but in 2002-03 is around $£ 9,000$ per annum for the 2 pre-clinical years and $£ 17,000$ per annum for the 3 clinical years. Overseas fee-paying students account for only $4 \%$ of the population, but for $6 \%$ among the dropouts.

Prior to entering university, most UK students study in secondary school towards qualifications the level of performance in which will determine the success of their applications to higher education. Broadly, we can distinguish between two types of school: those which are in the private sector (henceforth, 'Independent' schools) and those that are in the broadly-defined state sector. The latter consists of various sub-categories of school, including local education authority (LEA) comprehensive schools, grammar schools (to which admission is selective and subject to educational tests) and colleges of further education. In the school population of the UK as a whole, about $7 \%$ of pupils attend an Independent school. In contrast, around $34 \%$ of medical students went to an Independent school. This is markedly higher even than the $27 \%$ observed for the group of all (nonmedical) UK university students.

The pre-university secondary school qualifications that form the basis for offers of places at medical schools are, typically, 'A-levels' for school pupils from England, Wales and Northern Ireland, and 'Highers' for school pupils from Scotland. A-levels are classified as A through to $\mathrm{E}$. These grades can be converted into a points score: $\mathrm{A}=10$ points, $\mathrm{B}=8$ points, $\mathrm{C}=6$ points, $\mathrm{D}=4$ points, and $\mathrm{E}=2$ points. Highers are classified as $\mathrm{A}$ through to $\mathrm{C}: \mathrm{A}=3$ points, $\mathrm{B}=2$ points and $\mathrm{C}=1$ point. Offers of university places are typically conditional on the candidate's performance in their best three A-levels (or best five Highers). In addition, a number of medical schools interview candidates prior to making an offer of a place on the course. 
The average A-level (Higher) score from the best three (five) subjects was 26.2 (13.7) points, with some $27 \%$ of the cohort having the maximum 30 (15) points. Approximately $50 \%$ of students arriving for a medical degree had either A-levels or Highers in Chemistry, Physics and Biology. Not all medical students enter with the standard 'A-Level' or 'Higher' qualifications. About $4 \%$ of students had no prior qualifications recorded or only had Business and Technology Education Council (BTEC) or similar qualification. In addition, another $4 \%$ already had a prior qualification obtained from a university in the UK.

The social class background of students entering a medical degree program shows that around 34\% come from Social Class I (Professional) (with 39\% of these actually coming from a background in which one of the parents or the guardian is a medical practitioner) and $38 \%$ from Social Class II (Intermediate professions). This compares with only $19 \%$ of all students starting a 3 or 4-year degree coming from a Professional background and $43 \%$ from an Intermediate one.

Summarising with respect to the characteristics of those among the dropout sample, compared to those who successfully complete the degree program, there is a slightly larger proportion of individuals, (i) aged more than 19, (ii) who are men, (iii) paying non-UK fees, (iv) who have an average A-Level score which is slightly lower than $A B B$, and (v) who have more than the standard 3 A-Levels.

\section{Econometric Model}

In the current paper, our objective is to model the conditional probability that an individual student will drop out of a medical degree program during some small time interval, conditional on not having dropped out up to that point. As indicated above, the underlying variable is the time spent on the program rather than calendar time. Unlike in conventional duration (survival) models, two specific characteristics of the program need to be addressed. 
First, the program duration is limited to five years. Because of this limited duration, the underlying continuous time duration variable will have a distribution that is continuous over the interval $(0,5)$ and a discrete probability mass at the end point of 5 years. Second, the program cannot be completed before the end of five years. That is, the probability of successfully completing the program during the first five years is zero. We are not aware of any previous study applying a hazard model to the analysis of the undergraduate dropout probability. Mealli, et al. (1996) consider a duration-limited competing risks model in the context of Youth Training Programs. Booth and Satchell (1995), and van Ours and Ridder (2000) look at a related model for PhD completion rates.

\subsection{Cox's Proportional Hazards Model}

We start with the Cox's proportional hazards model. Given the above characterisation of the program of studies, the hazard for individual $i, h_{\mathrm{i}}(t)$, is parameterised as

$$
h_{\mathrm{i}}(t)=\lambda(t) \exp \left(\mathbf{x}_{\mathrm{i}}{ }^{\prime} \boldsymbol{\beta}\right) \quad(t<5 \text { years })
$$

where $\lambda(\mathrm{t})$ is the baseline hazard at time $t, \mathbf{x}_{\mathrm{i}}$ is the vector of characteristics for individual $i$ (excluding the intercept term) and $\beta$ is the corresponding vector of unknown coefficients. As discussed earlier, because of possible measurement errors in the recording of the date of dropout, for the purpose of the analysis presented here, the duration information has been recoded in terms of whole years completed. A recorded duration of $t$ whole years therefore indicates duration on the continuous time-scale, between $t-1$ and $t$ years. Hence, the probability of exiting by time $t$ conditional on $\mathbf{x}_{\mathrm{i}}$, given that the student was still on the program at time $t-1$ is given by

$$
q_{1 \mathrm{i}}\left(t \mid \mathbf{x}_{i}\right)=\operatorname{Prob}\left[T_{i}<t \mid t-1 \leq T_{i}\right]=1-\exp \left\{-\int_{t-1}^{t} h_{\mathrm{i}}(\tau) d \tau\right\}
$$




$$
\begin{aligned}
& =1-\exp \left[-\int_{t-1}^{t} \lambda(\tau) \exp \left\{\mathbf{x}_{i}{ }^{\prime} \boldsymbol{\beta}\right\} d \tau\right] \\
& =1-\exp \left[-\exp \left\{\mathbf{x}_{i}{ }^{\prime} \boldsymbol{\beta}+\delta(t)\right\}\right] \\
\text { where } \quad \delta(t) & =\ln \left\{\int_{t-1}^{t} \lambda(\tau) d \tau\right\}
\end{aligned}
$$

We thus have an Extreme-value form for the drop-out probability model in discrete time. See Narendranathan and Stewart (1993a, 1993b) for a model of unemployment duration in discrete time.

As seen earlier, the degree program finishes at the end of year 5. There is thus a forced termination at this point. Because of possible endogeneity, we do not make any distinction between those who had an intercalated year to complete a science degree and those who did not. In order to account for the forced termination, we assume that these limit point probabilities take the same Extreme-value form as before, but with a different set of coefficients. This is specified as

$$
\begin{aligned}
& q_{2 \mathrm{i}}\left(t=5 \mid \mathbf{x}_{\mathrm{i}}\right)=\operatorname{Prob}\left[\text { dropping out in year } 5 \mid \text { survival up to year } 5, \mathbf{x}_{\mathrm{i}}\right] \\
& =1-\exp \left[-\exp \left\{\mathbf{x}_{i}{ }^{\prime} \boldsymbol{\alpha}+\eta\right\}\right]
\end{aligned}
$$

where $\alpha$ is the vector of unknown coefficients and $\eta$ is the intercept term.

Let $T_{\mathrm{i}}$ be the recorded duration in years for individual $i$. Then the likelihood contribution by individual $i$ with a recorded duration of $T_{\mathrm{i}}<5$ is given by

$$
L_{i}=q_{1 \mathrm{i}}\left(T_{i}\right) \prod_{t=2}^{T_{i}}\left(1-q_{1 i}(t-1)\right)
$$

The likelihood contribution by individual $i$ who proceeds to year 5 is given by 


$$
L_{i}=\left[\left(1-q_{2 i}\right) \prod_{t=2}^{5}\left(1-q_{1 i}(t-1)\right)\right]^{\left(1-d_{i}\right)}\left[q_{2 i} \prod_{t=2}^{5}\left(1-q_{1 i}(t-1)\right)\right]^{d_{i}}
$$

where $d$ is a binary variable which takes the value of 1 if the individual drops out during the final year of the program, and is equal to zero otherwise. The likelihood function, which will be made-up of terms given by equations (5) and (6), will factor into two parts and thus facilitate separate estimation of the parameters of the two exit probabilities. The above model also can be thought of in a competing-risks framework where the two risks faced by the individuals are completion and dropping out. Since the degree program lasts for a minimum of five years, the completion specific hazard has to be set equal to zero for the periods up to the 5 years. This model then collapses to the one specified above.

A useful way of looking at the above specification is in terms of a binary response model. In the estimation of the first exit probability $q_{1}$, the dependent variable can be thought of as taking the value of 0 in the years prior to exit and a value of 1 in the year of exit prior to year 5. Each individual will make a maximum of 4 contributions to the estimation here. An individual who proceeds to the final year will have a binary sequence, which is entirely made-up of zeros. The estimation of the parameters of the second hazard is then carried using only the sub-sample of individuals who have proceeded to the final year of the program. This again can be thought of as a simple binary response model where the dependent variable is $d$, as defined above.

The main advantage of working within the binary variable framework is that we are then able to relax the extreme value assumption and use popular models such as probit and logit that imply a non-proportional hazard in the underlying continuous time framework. For example, in the case of a logit model, the conditional probabilities $q_{1 i}$ and $q_{2 i}$ will be specified as, 


$$
q_{1 i}(t)=\exp \left(\mathbf{x}_{i}^{\prime} \boldsymbol{\beta}+\delta(t)\right) /\left[1+\exp \left(\mathbf{x}_{i}^{\prime} \boldsymbol{\beta}+\delta(t)\right)\right]
$$

and

$$
q_{2 i}=\exp \left(\mathbf{x}_{i}{ }^{\prime} \boldsymbol{\alpha}+\eta\right) /\left[1+\exp \left(\mathbf{x}_{i}{ }^{\prime} \boldsymbol{\alpha}+\eta\right)\right]
$$

and these conditional probability functions are then used in equations (5) and (6). Unlike the extreme value distribution, probit and logit distributions are symmetric with respect to their means, although they do differ in the tail behaviour.

\subsection{Unobserved heterogeneity}

It is well known that failure to control for any unobserved individual-specific effects that may affect the hazard function will result in misleading inference due to inconsistent parameter estimators (Lancaster, 1990). The previous model can be extended for this purpose by including a random error term along with the vector of characteristics $\mathbf{x}$. This requires an assumption regarding the distribution of this unobservable individual-specific error term. In addition, we also require the assumption of independence of the unobservables and the included regressors in order to marginalise with respect to these unobservables. The models for the unobservables that were tried were: normally distributed unobservables, normally distributed unobservables with allowance for different masses at the end points, and a two mass point discrete distribution. In none of the models we estimated could we find any evidence of unobservable heterogeneity. Models which allowed for unobserved heterogeneity always converged to the same point as models without unobservables, and hence we report results only from the latter.

\subsection{Multi-level Models: Fixed vs random medical school effects}

One further issue that needs addressing is the issue of possible clustering of dropout rates within universities given the hierarchical nature of our dataset. We therefore need to allow for 
unobservable medical school factors to affect student dropout probabilities. We can either treat the unobservable medical school effects as fixed or as random. The first model is known as the fixed effects (FE) model and the second one as the random effects (RE) model. These models are known as multi-level models in the statistical literature. The FE model can be thought of as providing inferences conditional on the medical schools in the sample. On the other hand, the RE model can be thought of as providing marginal inferences that will enable us to generalise our results to the population of all medical schools. We consider the FE model as more appropriate for our analysis as the data and the sample analysed covers the full population of medical schools in the United Kingdom. We therefore include a set of medical school indicator variables and estimate the effects as part of the parameters of the model (Model 1). However, we also provide estimates obtained under the assumption of a RE model in order to make comparisons across different specifications.

There are advantages and disadvantages to the two approaches, which should be borne in mind in the comparisons of estimates across different models. The FE model does not allow one to include medical school characteristics in addition to the medical schoolspecific binary indicator variables, hence, we also estimate our FE model by replacing the medical school indicator variables by a set of medical school characteristics (Model 2). This problem is not present in the RE model since the medical school effects are assumed to be random drawings from a particular distribution. But, in order to marginalise the likelihood function with respect to the unobservables in this model, one needs to assume that the included covariates and the random effects are independently distributed. Although the RE model treats the unobserved medical school effects as random drawings from a distribution, one could obtain the estimates of 'shrunken' residuals (or empirical Bayes estimates) of these effects (Goldstein, 1995), which can then be compared to the estimated medical school 'fixed-effects'. Because we are dealing with very large numbers of observations per 
university, we expect to see the estimated medical school effects to be very similar across these models. In this specification, we assume that the unobservable medical school-specific random effects are drawn from a normal distribution. All models were estimated using Stata7 (2001) and gllamm written by Rabe-Hasketh et. al (2001).

\subsection{Model specification}

Analysis of student dropout behaviour has received much attention in the US, where one of the most influential theoretical explanations of student attrition is the path analyses model of Tinto $(1975,1987)$. This model and related analyses suggest that the major determinants of completion are likely to be the student's (i) academic preparedness, and (ii) social and academic integration into the educational institution. The analysis identifies a number of key influences on the withdrawal probability, including: the student's previous schooling, prior academic performance, family background and personal characteristics, as well as institutional characteristics. All covariates in the model refer to first year of the program. In our model of student dropout probabilities, we include control variables reflecting the student's prior academic preparedness, their social background, and personal characteristics. In an analysis of the dropout behaviour of all UK University students matriculating in 1989, Smith and Naylor (2001b) find evidence in support of a role for both academic preparedness and social integration. Previous schooling includes both prior qualifications of students and the type of school attended prior to university. Part of the motivation for the latter comes from the general issue of the impact of school quality and school type on later outcomes (see Moffit (1996)). As discussed in the previous sub-section, in one of our models we include dummy variables for the medical school attended (Model 1). Due to small cell sizes and the amalgamation of some London medical schools over our sample period, the University of London medical schools were treated as a single medical school. In a second model (Model 2), we replace the medical school dummy variables with a set of variables measuring 
characteristics of the medical school attended by the student. The third model presented is the RE version of Model 1 (Model 3).

In order to obtain data on a satisfactory number of dropouts in each year of the program, the models have been estimated by combining the 1985 and 1986 entry cohorts, with a year dummy included to account for any aggregate time effect. The dependent variable takes the value of one in a year if the individual drops out of the program in that year and zero otherwise. Because of the very small number of withdrawals after year four, the final year conditional exit probability refers to year four or year five. We thus have one conditional exit probability model for years 1 to 3 (see $q_{1}$ in equation (2)), which models the dropout/continuation process, and another specification for the rest of the period $\left(q_{2}\right.$ in equation (4)), which models the dropout/completion process.

Prior to the discussion of the results, we consider the choice of the distributional assumptions used for our models. Three types of model we used - Extreme value, logit and probit. Among the distributions probit performs poorly, although there is essentially no difference between the extreme value model and the logit model. The estimated marginal effects were very similar across the extreme value and the logit models. The restriction that the effects of the covariates are the same in both the drop-out probabilities $q_{1}$ and $q_{2}$ in the logit specification is easily rejected by the data. On the basis of this, we choose the logit model with unrestricted coefficients across the two dropout probabilities as our preferred model for both the FE and RE models.

\section{Empirical Results}

The derived marginal effects on the rates of withdrawal and the corresponding $p$-values for the estimated logit models are reported in Table 3. Model 1 includes a set of medical school indicator variables among the covariates. The results from Model 1 are presented in columns 
[1] and [2]. This is the fixed effects model (FE) where the unobservable medical school effects are treated as fixed numbers. In order to investigate further the ceteris paribus effects of medical schools, as discussed earlier, we also experimented by replacing the dummies with some variables that reflected the nature of the medical faculty in that particular university. These were: number of undergraduates, number of postgraduates on taught degrees, number of postgraduates on research degrees, expenditure on salaries per medical student, expenditure per medical student from research grants, percentage of professors among the staff in the faculty, percentage of senior staff, percentage of research staff, separate binary indicators for London, Scottish, Welsh and Irish universities. Results from substituting the medical school dummies with medical school characteristics, labelled Model 2, are presented in columns [3] and [4]. Columns [5] and [6] report results from the random effects (RE) model where the medical school unobservable effects as treated as random drawings from a normal distribution and labelled Model 3. Columns [1], [3] and [5] refer to the conditional drop-out/continuation probabilities $\left(q_{1}\right)$, and [2], [4] and [6] to the conditional dropout/completion probabilities $\left(q_{2}\right)$.

First, we note that the estimated marginal effects from these three models are broadly similar. The restriction that the medical school characteristics can be used in the model in place of the binary medical school indicators in the $q_{2}$ probability is rejected very easily $\left(\chi^{2}(6)=45.6[0.000]\right)$, but in the $q_{1}$ probability it is not rejected at $5 \%$ significance level $\left(\chi^{2}(6)=12.26[0.057]\right)$. We also find that the maximised value of the log likelihood is highest for both $q_{1}$ and $q_{2}$ from Model 1 (the FE model). One advantage of treating the unobservable medical school effects as random is that we can include medical school characteristics as additional covariates. But having included the medical school characteristics in Model 3 (or equivalently medical school random effects in Model 2), we were unable to reject the hypothesis of a zero variance on the random effects at all conventional significance levels, 
that is, the additional medical school characteristics seem to completely wipe-out all the unobservable medical school specific variations. Hence we only present results for Model 3 without additional medical school characteristics and for Model 2 without additional medical school random effects. We first discuss the results from Model 1 and then highlight the differences between these results and those of Model 2 and Model 3.

Significant age effects are found only in $q_{2}$. These suggest that conditional on progressing to the final years of the program, relative to someone who is 18 at the time of enrolment, an individual who is aged 22 or more, is estimated to have an increased withdrawal rate of 2.8 percentage points, ceteris paribus. Males are found to be significantly more likely to withdraw than females during all parts of the program.

Fee status is not found to play a significant role in the dropout behaviour, but nationality has a significant effect in the latter part of the program. A student who is a British national is found to be 0.63 percentage points more likely to dropout during the latter part of the program compared to someone who is a foreign national, ceteris paribus.

There are very strong and well-determined coefficients on prior qualifications. These effects are picked up by various binary indicator variables on the type of prior qualifications as well as by the actual scores obtained for students who had taken either A-Level or Higher qualifications. With respect to performance at A-Level or in Highers, we note that although it is customary in UK medical schools to require a student to obtain three (five) A-Level (Higher) passes prior to entry, some students do more subjects than the required number. In order to allow for this, we include the actual scores they obtained in their best three (five) ALevel (Higher) examinations and also the scores from the rest, if they had more than the required number. As expected, the effect from A-levels on the drop-out probability during the entire degree program period is estimated to be negative and declining towards the final years of the program. An extra two points on the A-Level average (equivalent to an extra A-Level 
grade) reduces the drop-out probability by about 0.15 percentage points, ceteris paribus, during the earlier parts of the programme, and by about 0.11 percentage points in the final year of the programme. However, other A-level scores additional to those achieved in the student's best 3 A-levels had no significant effect on the dropout probability. In contrast, the 'Highers' score from the best five subjects is not found to have a significant effect, although students who have more than the five minimum required 'Highers' are found to be significantly less likely to drop out in the early parts of the programme. In addition to the effect coming via the total A-Level (Highers) score, we also find that those students who entered with the maximum possible score for their best three (five) A-Level (Highers) subjects were significantly less likely to drop out during the early part of the program. The finding that the student's level of performance at A-level (Highers) has statistically significant effects on the drop-out probability is in line with the hypothesis that academic preparedness for a medical degree is an important factor determining continuation and completion.

Looking at A-level (Higher) subjects, assuming that a strong background in Biology, Chemistry and Physics is likely to be appropriate for medical students, we include three dummy variables for those students who have none, one, or three of these subjects. An original specification had dummies for whether the student had A-levels (Highers) in Physics, Chemistry or Biology or some combination of these. Results in Table 3 are arrived at having tested the implied restrictions. Relative to those with just two of the three of these subjects, students who enter not having done any of these subjects are found to be significantly more likely to drop out during the first few years of the program, but this effect is completely reversed in the final year. As expected, students with all three of these subjects are found to have a lower probability of withdrawal relative to those with only two of the three subjects, ceteris paribus. Whether a student enters with only one of these subjects or two of these 
subjects out of the three preferred ones is not found to make any difference to the withdrawal probabilities. Interestingly, there does not seem to be any additional effect coming via the possession of 'A-Level' or 'Highers' in Mathematics.

We find that students who enter with qualifications other than the standard 'A-Levels' or 'Highers' are significantly less likely to dropout during the early parts of the program. For example, students who had previously obtained a UK university qualification are more likely to continue beyond the third year. There was no significant effect in the final part of the program.

It has been argued that the A-level performance of students from the non-Independent school sector might be an under-estimate of their underlying ability and hence the negative effect of A-level performance might be lower for ex-pupils of state-schools compared to Independent schools (see, for example, Smith and Naylor (2001a)). In order to test for these kinds of effects, we included binary indicators for school type and also interactions of these with the actual scores obtained in the main entry qualification. We did not find any significant effect of A-Level performance varying with the type of school, and therefore report in Table 3 only those results obtained without these interactions. The only consistently significant effect on withdrawal probabilities associated with the type of school attended was for students who had attended a College of Further Education. This significant negative effect was only present in the final year of the program.

The social class effects are found to be weak in general and show little impact. One exception is the significant negative effect for individuals from Social Class 'Intermediate' (SCII) on the withdrawal rate in the latter parts of the program for students. We also note that a student whose parent is a medical practitioner is less likely to withdraw, although the effect is not well determined. We have also interacted prior academic performance with social class background, but find no significant effects. 
From Model 1, the estimated coefficients on the medical school indicator variables permit the construction of a ranking of medical schools. In Figure 1 we plot, for illustrative purposes, for the $q_{1}$ probability, the estimated medical school effects (marked with a $\times$ ) along with their $95 \%$ confidence intervals. We find only a few of the individual institution effects are significantly different from the median medical school, with five (one) significantly above (below) the median.

In Model 2 we replace the binary indicator variables for medical school attended with various medical school characteristics. The results for the Model 2 specification are reported in Columns [3] and [4] of Table 3. Although the estimated marginal effects in the $q_{1}$ probability were broadly similar across the two models, there were some notable exceptions in $q_{2}$. The absolute magnitude of the estimated marginal effects in the $q_{2}$ in Model 2 was typically higher compared to Model 1 . Of the effects of the medical school characteristics themselves, we note from Table 3 that there is evidence that the drop-out probability is lower the fewer students there are on the degree programme and the greater the number of postgraduate research students in the medical school.

We next turn to the results reported in Columns [5] and [6] of Table 3. This refers to Model 3 which is based on the RE specifications. First, we note that a test of $\mathrm{H}_{0}$ : variance $=0$ can be tested as a likelihood ratio test but the statistic will not be a standard chi-squared, since the parameter restriction is on the boundary of the parameter space. The standard likelihood ratio statistic has a probability mass of 0.5 at zero and $0.5 \chi^{2}(1)$ for positive values. Thus a one-sided 5\% significance level requires the use of the 10\% critical value (Lawless (1987)). The likelihood ratio statistic for testing that the variance of the medical school random effects is zero is 30.12 in model for $q_{1}$ and 54.96 in model for $q_{2}$, both of which are easily rejected at conventional levels of significance. 
We turn next to the estimated effects of the covariates and simply note that the effects are very similar to the effects obtained from Model 1 . This should not be surprising since, because of our extremely large sample of student population in each medical school, we would expect the RE and the FE estimates of the unobservable medical school effects to be the same.

As already noted, Figure 1 plots the estimated medical school coefficients from the FE (Model 1) for $q_{1}$. In addition, this figure also plots (for $q_{1}$ for the RE (Model 3)) the estimated shrunken residuals (empirical Bayes estimates) for each medical school (using the same medical school order as for the FE estimates) along with the $95 \%$ confidence intervals marked with a $\diamond$. From the RE model, seven medical schools are significantly above the median, although none are significantly below. It is clear from the figure how similar the estimated medical school effects are from the two models (with a rank correlation in excess of 0.98 ), although the effects from the RE model tend to be estimated more precisely.

\section{A Competing Risks Analysis}

The models that have been considered so far are for the conditional probability of withdrawal from the program, conditioned on not having withdrawn up to that point. These are a 'single risk' models, in the sense that no distinction is made between various alternative reasons for withdrawal. A student can withdraw from the program for reasons such as course transfers, academic failure, health problems, inter alia. Table 1, column 2, provides the breakdown of the number of dropouts by reason for withdrawal. Since in our model specification the continuation versus dropout probabilities $q_{1}$ was specified over the first three years of the program, we report the relevant frequencies for this part of the program only. We note that there were no withdrawals due to course change in years 4 or 5 . Of those students who dropped out of the medical program, the proportion of students who changed their course of study was about one-third. From the point of view of public policy-makers seeking to expand 
the number of fully-trained medical doctors, distinguishing between reasons for dropping out may not be important: a drop-out is a drop-out. Against this, strategies for minimising the drop-out rate might benefit from a better understanding of the nature of the dropout decision. Additionally, for the university in which the medical school is located, the distinction between transferring course and dropping out of the medical programme for other reasons may be particularly important if only the latter impacts adversely on the institution's performance indicator score.

In this section, since the FE model (Model 1) produced the highest maximised log likelihood value, we extend this model to the competing risks case where we distinguish between the reported reasons for the exit. See Narendranathan and Stewart (1993b) for an example of a hazard model with competing risks in the context of exiting from unemployment to employment. In the current paper, given the small number of exits, we consider only two possible alternative reasons for exit: a 'course transfer' or 'other reasons'. We wish to model the determinants of the conditional probability of exiting out of the medical program for one of these two reasons.

Two separate logit models were fitted, where in the model for dropout due to 'other reasons', a 'course transfer' is treated as a right-censored event, and vice-versa. The coefficient estimates for the conditional probability of exiting out of the medical program for 'other reasons' (Model 4a), and conditional probability of exiting out of the medical program because of 'course transfer' (Model 4b) are presented in column [2] and [3] of Table 4, respectively. For ease of comparison, the coefficient estimates from the single risk model (Model 1) are reproduced in column [1].

With respect to personal characteristics, age and gender effects are found to be significant only in the conditional probability for exiting due to reasons other than course transfers. In contrast, the nationality and fee status variables are found to exert a significant 
influence only on the 'course-transfer' conditional probability relative to progression. Unlike in the single risk model (Model 1), a student who attended a Grammar school compared to someone coming from a Local Education Authority school, prior to entry into medical school, is found to be significantly less likely to exit for 'other reasons', ceteris paribus.

With respect to prior qualifications, the total 'A-Level' scores in the best three subjects is found to play an important and significant role only in the exit probability associated with 'other reasons': although having achieved a top-score has a significant effect on both. We note that students with no favoured A-level subjects are significantly more likely to drop out for reasons other than course transfer. In contrast, having three, rather than two, favoured subjects significantly reduces the probability of transferring course: we infer from this that matching seems to be important.

The significant positive effect found for students coming from a 'skilled non-manual' social class background in Model 1 is now found to act via the risk associated with withdrawals for 'other reasons'. Interestingly, we also find that students coming from a medical background are no more or less likely to withdraw from the medical school, but are significantly less likely to transfer course. This result is consistent with the idea that such students have a greater commitment to their chosen course of medical study.

\section{Discussion and further remarks}

In the context of a shortage of trained doctors in the UK, government policy for the medical workforce rests on a plan to implement ongoing major expansion in total medical school intake (see MWSAC, 1997 and HEFCE, 2001). As part of the strategy of expansion, the Medical Workforce Standing Committee has called for research into the factors affecting medical student progression and withdrawal behaviour. A substantial body of previous work on UK university student withdrawal has exploited data on full cohorts of students but has 
omitted any analysis of medical students as it is generally accepted that, for a variety of reasons, the characteristics of medical students and their courses differ from those of other students and hence justify separate analysis. In this paper, we conduct a statistical analysis of the drop-out behaviour of UK medical students, exploiting data on full student cohorts.

Our statistical analysis extends previous research in the general area by adopting a hazard model to model the probability of dropping out. We also offer a competing-risks framework. The exit probability model is based on the initial distinction between dropping out and continuing and the subsequent distinction between dropping out and completing, conditional on continuation. For each of our single-risk models, we first considered two alternative specifications: in one, including binary indicator variables for the particular medical school attended (fixed effects model) and, in the other, incorporating medical school characteristics. We also re-estimated our single-risk model treating the unobserved medical school effects as random and found the results to be broadly similar to the fixed-effects model. The competing risks analysis distinguishes between dropping out because of course transfer and dropping out for all other reasons.

Our main finding is that academic preparedness is the major influence on medical student withdrawal. Students who scored highly in their pre-university qualifications (at Alevel or Highers, for example) are significantly less likely to drop out of medical school: they are both more likely to continue and more likely to complete than students performing less well prior to university. We also find that the choice of pre-university subjects exerts a significant influence over the medical student's dropout probability. For example, students who had taken Chemistry, Physics and Biology at A-level were significantly less likely to drop out than were students with only two (or fewer) of these three subjects. In particular, students with all three of Chemistry, Physics and Biology were significantly less likely to transfer from Medicine to some other course: we infer that the extent of the pre-university 
subject match is an important characteristic of medical students. This is not true for all university degree subjects (see Smith and Naylor, 2001b). On other entry qualifications, we find that medical students who had already obtained a UK university qualification are significantly less likely to drop out of medical school: this could have implications for a lower average drop-out rate on recently introduced postgraduate medical degree programmes.

Among other results, we also find that age and gender exert significant influences on dropout behaviour, with males and more mature students more likely to withdraw than females or younger students, respectively. Conversely, we find surprisingly little effect associated with either school or family social class background, although we do note that students with a medical doctor as a parent are significantly less likely to transfer out of a medical programme. We find that there are some significant differences in drop-out probabilities across the medical schools, after controlling for the students' observed characteristics. In the specifications based on medical school characteristics, we find evidence that the drop-out probability is lower in smaller medical schools and in medical schools with a high proportion of postgraduates on a medical programme. In terms of the debate on widening access into medical school for students who do not meet the traditional levels of attainment in their pre-university qualifications, our results raise the serious concern that, potentially, the ex ante completion probability of such students will be relatively low. This is not to argue against policies of widening access. It is to point out, however, that such policies may be most successfully accomplished if accompanied by complementary strategies of student support (including appropriate supplementary training) and by well-targeted recruitment activity. With respect to the latter, it has been shown that, for non-medical students, prior levels of attainment might under-predict university performance for students from certain backgrounds. For example, students who previously attended state schools tend to perform better at university than students from the independent school sector, ceteris 
paribus (see Smith and Naylor, (2001a)). Accordingly, in our current study of medical student dropout behaviour we have included controls both for previous school type and for potential interactions between prior qualification attainment and school type. We found no clear evidence of significant effects. Nor do we find significant interaction effects associated with family background and prior qualifications. It follows that if targeted recruitment to widen access is to be successful in minimising the impact on the dropout probability, targeting may need to be more precise than simply making differential offers according to school type, as has begun to occur elsewhere in the UK higher education sector. 


\section{References}

Angel, C. and Johnson, A. (2000) Broadening access to undergraduate medical education. British Medical Journal, 321,1136-8.

Arulampalam, W., Naylor, R. A. and Smith, J. (2003) Factors affecting the probability of first-year medical student dropout in the UK: a logistic analysis for the intake cohorts of 1980-1992. Mimeo, University of Warwick.

Booth, A. L. and Satchell, S. E. (1995) The hazards of doing a PhD: an analysis of completion and withdrawal rates of British $\mathrm{PhD}$ students in the 1980s. Journal of the Royal Statistical Society, Series A, (Statistics in Society), 158(2), 297-318.

Goldstein, H (1995) Multilevel Statistical Models. Second Edition, (Kendall's Library of Statistics,, vol. 3), Edward Arnold, London. HEFCE, 01/31, Report, May 2001, Increasing Medical Student Numbers in England, Higher Education Funding Council for England, Bristol.

Lancaster, T. (1990) The Econometric Analysis of Transition Data, Econometric Society Monograph, Cambridge University Press.

Lawless, J. F. (1987) Negative binomial and mixed Poisson regression. Canadian Journal of Statistics, 15, 209-25.

McManus, I. C. (1996) Drop-out rate in medical school seems reasonable (letter to the Editor). British Medical Journal, 313, July, 173.

McManus, I. C. (1998) Factors affecting likelihood of applicants being offered a place in medical schools in the United Kingdom in 1996 and 1997: retrospective study. British Medical Journal, 317, 1111-17. 
McManus, I. C., Richards P., and Winder, B. C. (1999) Intercalated degrees, learning styles, and career preferences: prospective longitudinal study of UK medical students. British Medical Journal, 319, 542-6.

Machin, S. and Oswald, A. (2000) UK economics and the future supply of academic economists. The Economic Journal, 110, F334-F349.

Mealli, F., Pudney, S. and Thomas, J. (1996) Training duration and post-training outcomes: a duration-limited competing risks model. The Economic Journal, 106, 422-33.

Medical Workforce Standing Advisory Committee. (1997) Planning the medical workforce: third report. London: Department of Health (a downloadable version of this report is available at http://www.doh.gov.uk/medical/mwsca3.htm).

Moffitt, R. (1996) Symposium on school quality and educational outcomes: introduction. Review of Economics and Statistics, 78, 559-61.

Narendranathan, W. and Stewart, M. B. (1993a) How does the benefit effect vary as unemployment spells lengthen?. Journal of Applied Econometrics, 8, 361-81.

Narendranathan, W. and Stewart, M. B. (1993b) Modelling the probability of leaving unemployment: competing risks models with flexible base-line hazards. Journal of the Royal Statistical Society, Series C, (Applied Statistics), 42(1), 63-83.

Parkhouse, J. (1996) Intake, output, and drop out in United Kingdom medical schools. British Medical Journal, 312, April, 885.

Porter, O. (1990) Undergraduate completion and persistence in four-year colleges and universities. The National Institute of Independent Colleges and Universities, Washington, D.C. 
Rabe-Hesketh, S., Pickles, A. and Skrondal, A. (2001) GLLAMM Manual, Technical Report 2001/01, Department of Bio-statistics and Computing, Institute of Psychiatry, King's College, University of London.

Smith, J. P. and Naylor, R. A. (2001a) Determinants of Individual Degree Performance. Oxford Bulletin of Economics and Statistics, 63(1), 29-60.

Smith, J. P. and Naylor, R. A. (2001b) Dropping out of university: a statistical analysis of the probability of withdrawal for UK university students. Journal of the Royal Statistical Society, Series A, (Statistics in Society), 164(2), 389-405.

Stata (2001), Statistical Software, Stata Corporation.

Tinto, V. (1975) Dropout from higher education: a theoretical synthesis of recent research. Review of Educational Research, 45, 89-125.

Tinto, V. (1987) Leaving college: rethinking the causes and cures of student attrition, Chicago, University of Chicago Press.

Van Ours, J. C. and Ridder, G. (2000) Fast track or failure: a study of the completion rates of graduate students in economics. Centre for Economic Policy Research, Discussion Paper, No. 2363. 
$\underline{\text { Table } 1}$

\begin{tabular}{|l|cc|cc|}
\hline & \multicolumn{2}{|c|}{ Overall dropout } & \multicolumn{2}{c|}{ Reason for dropout } \\
& & & Other \\
\hline \multicolumn{1}{|c|}{ Entry Year } & $\mathbf{1 9 8 5}$ & $\mathbf{1 9 8 6}$ & $\mathbf{1 9 8 5 + 1 9 8 6}$ & $\mathbf{1 9 8 5}+\mathbf{1 9 8 6}$ \\
Cumber of Students (initial) & 3889 & 3900 & 7789 & 7789 \\
Conditional dropout rate (\%) & & & & \\
Year 1 & 5.32 & 5.54 & 1.85 & 3.58 \\
Year 2 & 3.04 & 2.39 & 0.79 & 1.82 \\
Year 3 & 1.01 & 1.39 & 0.20 & 0.92 \\
Year 4 & 1.33 & 1.47 & 0.00 & 1.40 \\
Year 5 & 0.37 & 0.37 & 0.00 & 0.36 \\
Unconditional dropout rate \% & 10.67 & 10.74 & 2.77 & 8.09 \\
\hline
\end{tabular}


Table 2 - Definitions and Descriptive Statistics of Variables - Mean (Std. Deviation)

\begin{tabular}{|c|c|c|c|c|}
\hline Variable Name and Categories & Definitions & $\begin{array}{l}\text { Overall } \\
\text { sample }\end{array}$ & $\begin{array}{c}\text { Dropout } \\
\text { sample }\end{array}$ & $\begin{array}{c}\text { Completion } \\
\text { sample } \\
\end{array}$ \\
\hline \multicolumn{5}{|l|}{ Entry age (binary indicators) } \\
\hline Aged $\leq 18$ & Aged 18 or less in September of entry year & 0.619 & 0.573 & 0.625 \\
\hline Aged 19-21 & Aged 19-21 in September & 0.320 & 0.311 & 0.321 \\
\hline Aged $>21$ & Aged more than 21 in September & 0.061 & 0.116 & 0.054 \\
\hline Sex - male & $=1$ if the student is male & 0.543 & 0.586 & 0.538 \\
\hline Nationality & $=1$ if the student has British Nationality & 0.942 & 0.926 & 0.944 \\
\hline Non UK fee & $=1$ if the student pays non-UK fee & 0.042 & 0.058 & 0.040 \\
\hline Accommodation (binary indicators) & Accommodation in the first year at university & & & \\
\hline Living at home & Living at home & 0.110 & 0.118 & 0.108 \\
\hline Living on Campus & Living at university campus accommodation & 0.773 & 0.739 & 0.778 \\
\hline 'Other' & Not living at home or university campus. & 0.117 & 0.143 & 0.114 \\
\hline School Attended (binary indicators) & Type of school attended prior to entry into the medical program. & 0.381 & 0.382 & 0.381 \\
\hline Local Education Authority School & School is non-selective & & & \\
\hline Grammar School & State-funded, but selection is typically based on ability. & 0.135 & 0.101 & 0.139 \\
\hline Independent School & Fee paying school and is also selective & 0.343 & 0.333 & 0.344 \\
\hline College of Further Education & College of Further Education & 0.080 & 0.076 & 0.080 \\
\hline Other & Residual category which includes Church Schools & 0.061 & 0.108 & 0.056 \\
\hline Main Entry Qualifications & Type of qualifications the individual had on entry into the program. & & & \\
\hline A-Level scores - Best of 3 - total & $\begin{array}{l}\text { Best of three total A-Level scores (average among those with these } \\
\text { qualifications). This is a university entrance-level qualification, } \\
\text { which is typically taken at about age } 18 \text {. The scores are recorded in } \\
\text { steps of two and go from } 2 \text { to } 10 \text {. It is normal for a student to be } \\
\text { doing three of these. }\end{array}$ & $26.2(3.9)$ & $25.4(4.3)$ & $26.3(3.9)$ \\
\hline 'H' scores - best of 5 - total & $\begin{array}{l}\text { Best of five total Scottish/Irish Higher scores (average among those } \\
\text { with these qualifications). This is also a university entrance-level } \\
\text { qualification, which is typically taken at about age 18. The scores } \\
\text { are recorded in steps of one and goes from } 1 \text { to } 3 \text {. It is normal for a } \\
\text { student to be doing five of these. }\end{array}$ & $13.7(1.9)$ & $13.5(1.9)$ & $13.7(1.9)$ \\
\hline
\end{tabular}


Table 2 Continued

\begin{tabular}{|c|c|c|c|c|}
\hline Variable Name and Categories & Definitions & $\begin{array}{l}\text { Overall } \\
\text { sample }\end{array}$ & $\begin{array}{c}\text { Dropout } \\
\text { sample }\end{array}$ & $\begin{array}{c}\text { Completion } \\
\text { sample }\end{array}$ \\
\hline Percentage of students having more than $3 \mathrm{AL}$ & & 42.9 & 61.4 & 40.7 \\
\hline Other A-Level scores & Excludes the best 3 'A-Levels' & $8.9(4.9)$ & $13.3(6.1)$ & $8.1(4.2)$ \\
\hline Percentage of students having more than 5 ' $\mathrm{H}$ ' & & 7.2 & 7.7 & 7.1 \\
\hline Other ' $\mathrm{H}$ ' scores & Excludes the best 5 ' $\mathrm{H}$ ' scores & $2.8(1.3)$ & $2.7(1.3)$ & $2.8(1.3)$ \\
\hline Top Score & $\begin{array}{l}=1 \text { if the total score was the highest achievable (out of three for A-Level } \\
\text { subjects, and out of five for ' } H \text { ' level subjects }\end{array}$ & 0.272 & 0.139 & 0.288 \\
\hline One favoured subject & $\begin{array}{l}=1 \text { if subjects taken included one from (Chemistry, Physics, Biology) } \\
\text { among the 'A', 'H' subjects }\end{array}$ & 0.013 & 0.016 & 0.012 \\
\hline Two favoured subjects & $\begin{array}{l}=1 \text { if subjects taken included two from (Chemistry, Physics, Biology) } \\
\text { among the 'A' 'H' subjects }\end{array}$ & 0.439 & 0.474 & 0.435 \\
\hline Three favoured subjects & $\begin{array}{l}=1 \text { if subjects taken included Chemistry, Physics, and Biology among the } \\
\text { 'A', 'H' subjects }\end{array}$ & 0.503 & 0.416 & 0.513 \\
\hline \multicolumn{5}{|l|}{ Other Entry Qualifications (binary indicators) } \\
\hline A-Levels or Highers only & Students who have only A-levels or Scottish Highers & 0.920 & 0.868 & 0.925 \\
\hline UK university qualifications & These are mainly students who already have a degree & 0.039 & 0.056 & 0.038 \\
\hline 'Other' & Students with no qualification, BTEC ${ }^{1}$, other UK/foreign qualification. & 0.041 & 0.076 & 0.037 \\
\hline Parental Social Class (binary indicators) & Social class of the head of household. & & & \\
\hline Professional & (SC I) & 0.343 & 0.331 & 0.345 \\
\hline Intermediate & (SC II) & 0.383 & 0.342 & 0.388 \\
\hline Skilled Non-manual & (SC III NM) & 0.080 & 0.094 & 0.078 \\
\hline 'Other' & (SC IIIM, SC IV, SC V) Manual/other workers including non-workers & 0.194 & 0.233 & 0.189 \\
\hline Father is a Doctor & Parent/guardian was a medical practitioner & 0.137 & 0.126 & 0.139 \\
\hline Number of Students & & 7789 & 834 & 6955 \\
\hline
\end{tabular}

NOTE: 1 BTEC is the abbreviation for Business and Technology Education Council 
Table 3

Derived Marginal Effects $(\times 100)$ [p-values] on the Conditional Exit Probability of Withdrawal from the Medical Degree Program Logit Models

\begin{tabular}{|c|c|c|c|c|c|c|}
\hline \multirow{2}{*}{ Variable } & \multicolumn{2}{|c|}{$\begin{array}{l}\text { With university dummies (FE) - } \\
\text { MODEL } 1\end{array}$} & \multicolumn{2}{|c|}{$\begin{array}{c}\text { With university characteristics }{ }^{3,4}- \\
\text { MODEL } 2\end{array}$} & \multicolumn{2}{|c|}{$\begin{array}{l}\text { Random University Effects (RE) - } \\
\text { MODEL } 3\end{array}$} \\
\hline & 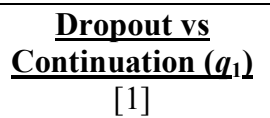 & $\frac{\frac{\text { Dropout vs }}{\text { Completion }\left(q_{2}\right)}}{[2]}$ & 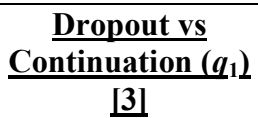 & 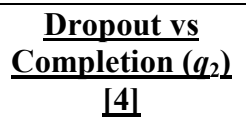 & 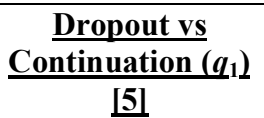 & 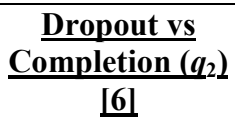 \\
\hline Intercept & $-2.248[0.02]^{* *}$ & $-4.512[0.00]^{* *}$ & $-1.055[0.54]$ & $-3.527[0.02]^{* *}$ & $-2.037[0.05]^{*}$ & $-3.927[0.00]^{* *}$ \\
\hline Time trend ${ }^{5}$ & $-1.743[0.00]^{* *}$ & & $-1.764[0.00]^{* *}$ & & $-1.882[0.00]^{* *}$ & \\
\hline 1986 Year Dummy & $0.061[0.73]$ & $0.033[0.82]$ & $-0.662[0.05]^{* *}$ & $-0.212[0.45]$ & $0.055[0.78]$ & $0.033[0.82]$ \\
\hline \multicolumn{7}{|l|}{ Entry Age $($ Aged $\leq 18)$} \\
\hline Aged 19-21 & $-0.094[0.65]$ & $0.435[0.05]^{* *}$ & $-0.056[0.79]$ & $0.533[0.04]^{* *}$ & $-0.116[0.61]$ & $0.391[0.03]^{* *}$ \\
\hline Aged $>21$ & $1.035[0.11]$ & $2.776[0.02]^{* *}$ & $1.153[0.09]^{*}$ & $3.428[0.02]^{* *}$ & $0.965[0.06]^{*}$ & $1.251[0.00]^{* *}$ \\
\hline Sex - male & $0.346[0.06]^{*}$ & $0.498[0.00]^{* *}$ & $0.367[0.05]^{* *}$ & $0.549[0.00]^{* *}$ & $0.374[0.06]^{*}$ & $0.490[0.00]^{* *}$ \\
\hline British National & $-0.834[0.13]$ & $0.625[0.00]^{* *}$ & $-0.860[0.13]$ & $0.667[0.00]^{* *}$ & $-0.783[0.09]^{*}$ & $1.029[0.00]^{* *}$ \\
\hline Non UK fee student & $-0.331[0.50]$ & $0.549[0.31]$ & $-0.459[0.33]$ & $0.675[0.30]$ & $-0.489[0.43]$ & $0.468[0.14]$ \\
\hline \multicolumn{7}{|c|}{ Accommodation (Living at home) } \\
\hline Campus & $-0.253[0.48]$ & $0.417[0.04]^{* *}$ & $-0.223[0.52]$ & $0.365[0.13]$ & $-0.237[0.52]$ & $0.457[0.09]^{*}$ \\
\hline 'Other' & $0.470[0.29]$ & $0.674[0.18]$ & $0.494[0.27]$ & $0.396[0.38]$ & $0.476[0.25]$ & $0.424[0.15]$ \\
\hline \multicolumn{7}{|l|}{ School Attended (LEA) } \\
\hline Grammar School & $-0.460[0.13]$ & $-0.152[0.50]$ & $-0.496[0.10]^{*}$ & $-0.161[0.55]$ & $-0.590[0.11]$ & $-0.095[0.71]$ \\
\hline Independent School & $0.101[0.67]$ & $-0.057[0.76]$ & $0.094[0.69]$ & $-0.112[0.60]$ & $0.156[0.53]$ & $-0.069[0.72]$ \\
\hline College of Further Education & $0.217[0.57]$ & $-0.407[0.07]^{*}$ & $0.216[0.57]$ & $-0.451[0.10]^{*}$ & $0.230[0.54]$ & $-0.530[0.19]$ \\
\hline 'Other' & $0.036[0.95]$ & $0.747[0.23]$ & $0.022[0.97]$ & $0.658[0.31]$ & $0.099[0.87]$ & $0.514[0.12]$ \\
\hline \multicolumn{7}{|l|}{ Main Entry Qualifications } \\
\hline A-Level scores & $-0.077[0.01]^{* *}$ & $-0.053[0.02]^{* *}$ & $-0.077[0.01]^{* *}$ & $-0.066[0.01]^{* *}$ & $-0.082[0.01]^{* *}$ & $-0.049[0.03]^{* *}$ \\
\hline 'H' scores & $-0.034[0.61]$ & $-0.058[0.27]$ & $-0.029[0.67]$ & $-0.059[0.33]$ & $-0.039[0.61]$ & $-0.049[0.33]$ \\
\hline Other 'A'/'AS' Level scores & $-0.015[0.54]$ & $0.013[0.49]$ & $-0.018[0.47]$ & $0.004[0.86]$ & $-0.013[0.61]$ & $0.011[0.55]$ \\
\hline Other 'H' scores & $-0.173[0.05]^{* *}$ & $-0.084[0.29]$ & $-0.181[0.04]^{* *}$ & $-0.157[0.09]^{*}$ & $-0.193[0.05]^{* *}$ & $-0.088[0.25]$ \\
\hline Achieved Top Score & $-1.064[0.00]^{* *}$ & $0.117[0.62]$ & $-1.046[0.00]^{* *}$ & $0.087[0.75]$ & $-1.158[0.00]^{* *}$ & $0.104[0.63]$ \\
\hline Has Maths 'A' Level/Higher & $0.180[0.54]$ & $0.099[0.67]$ & $0.190[0.53]$ & $0.131[0.63]$ & $0.190[0.56]$ & $0.119[0.61]$ \\
\hline No favoured subject & $2.686[0.06]^{*}$ & $-0.575[0.01]^{* *}$ & $2.741[0.06]^{*}$ & $-0.695[0.00]^{* *}$ & $1.992[0.01]^{* *}$ & $-0.869[0.18]$ \\
\hline One favoured subjects & $-0.016[0.98]$ & $-0.422[0.14]$ & $0.026[0.97]$ & $-0.458[0.19]$ & $-0.010[0.99]$ & $-0.588[0.34]$ \\
\hline Three favoured subjects & $-0.527[0.06]^{*}$ & $-0.339[0.12]$ & $-0.547[0.06]^{*}$ & $-0.451[0.08]^{*}$ & $-0.586[0.05]^{*}$ & $-0.315[0.14]$ \\
\hline
\end{tabular}


Table 3- Continued

\begin{tabular}{|c|c|c|c|c|c|c|}
\hline \multirow[t]{2}{*}{ Variable } & \multicolumn{2}{|c|}{$\begin{array}{c}\text { With university dummies (FE) - } \\
\text { MODEL } 1\end{array}$} & \multicolumn{2}{|c|}{$\begin{array}{c}\text { With university characteristics - } \\
\text { MODEL } 2\end{array}$} & \multicolumn{2}{|c|}{$\begin{array}{c}\text { Random University Effects (RE) - } \\
\text { MODEL } 3\end{array}$} \\
\hline & $\frac{\begin{array}{c}\text { Dropout vs } \\
\text { Continuation }\left(q_{1}\right)\end{array}}{[1]}$ & $\frac{\begin{array}{c}\text { Dropout vs } \\
\text { Completion }\left(q_{2}\right)\end{array}}{[2]}$ & 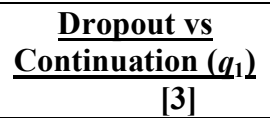 & $\frac{\begin{array}{c}\text { Dropout vs } \\
\text { Completion }\left(q_{2}\right)\end{array}}{[4]}$ & 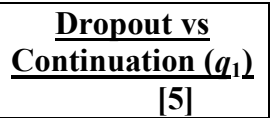 & $\frac{\begin{array}{c}\text { Dropout vs } \\
\text { Completion }\left(q_{2}\right)\end{array}}{[6]}$ \\
\hline Other Entry Quals (A-levels/Highers) & & & & & & \\
\hline UK university qualifications & $-1.460[0.00]^{* *}$ & $0.442[0.37]$ & $-1.481[0.00]^{* *}$ & $0.420[0.43]$ & $-2.289[0.00]^{* *}$ & $0.328[0.31]$ \\
\hline $\begin{array}{l}\text { Other } \\
\text { Parental Social Class (Professional) }\end{array}$ & $-1.993[0.00]^{* *}$ & $0.132[0.82]$ & $-1.995[0.00]^{* *}$ & $0.137[0.84]$ & $-3.883[0.00]^{* *}$ & $0.091[0.86]$ \\
\hline Intermediate & $-0.094[0.71]$ & $-0.381[0.03]^{* *}$ & $-0.091[0.72]$ & $-0.456[0.03]^{* *}$ & $-0.113[0.68]$ & $-0.396[0.04]^{* *}$ \\
\hline Skilled Non-manual & $0.756[0.09]^{*}$ & $-0.158[0.52]$ & $0.719[0.11]$ & $-0.245[0.36]$ & $0.700[0.07]^{*}$ & $-0.172[0.56]$ \\
\hline 'Other' & $0.310[0.32]$ & $-0.159[0.40]$ & $0.322[0.31]$ & $-0.200[0.36]$ & $0.309[0.32]$ & $-0.163[0.45]$ \\
\hline Father/Guardian is a Doctor & $-0.215[0.48]$ & $-0.169[0.43]$ & $-0.207[0.50]$ & $-0.195[0.44]$ & $-0.224[0.52]$ & $-0.189[0.45]$ \\
\hline $\begin{array}{l}\text { Medical school characteristics } \\
\text { Number of undergraduates } \\
\text { Number of taught postgraduates } \\
\text { Number of research postgraduate } \\
\text { Salaries/medical student ( } £ 000 \mathrm{~s}) \\
\text { Other exp./medical student } £ 000 \mathrm{~s}) \\
\text { Percentage of all staff - Professors } \\
\text { Percentage of all staff - Senior } \\
\text { Percentage of all staff - Research }\end{array}$ & & & $\begin{array}{l}0.001[0.37] \\
0.008[0.05]^{* *} \\
-0.010[0.31] \\
0.047[0.01]^{* *} \\
0.097[0.33] \\
-0.146[0.05]^{* *} \\
-0.028[0.36] \\
0.011[0.43]\end{array}$ & $\begin{array}{c}0.002[0.03]^{* *} \\
0.004[0.24] \\
-0.024[0.01]^{* *} \\
-0.005[0.74] \\
-0.042[0.63] \\
0.128[0.04]^{* *} \\
-0.093[0.01]^{* *} \\
0.028[0.03]^{* *}\end{array}$ & & \\
\hline Treatment of University effects & Fixed & Fixed & Excluded & Excluded & Random & Random \\
\hline LR test for the variance of the $\mathrm{RE}=0$ & & & & & $30.12[0.000]$ & $54.96[0.000]$ \\
\hline Maximised log likelihood value & -2935.49 & -507.77 & -2941.62 & -530.56 & -2958.42 & -529.82 \\
\hline Number of observations & \multicolumn{2}{|c|}{7789} & \multicolumn{2}{|c|}{7789} & \multicolumn{2}{|c|}{7789} \\
\hline
\end{tabular}

Notes:

1. For classes of dummy variables the default class is indicated in parentheses.

2. ** indicates significance at the $1 \%$ level, * indicates significance at the $5 \%$ level.

3. Model 2 additionally includes, individual dummies for the University of London, Scottish universities, a Welsh university, and an Irish university.

4. When random effects were added to Model 2, the random effect variances were insignificantly different from zero.

5. The LR statistic for testing this specification in the model with separate time dummies was 0.22 [0.99] for Model 1 and 0.24 [0.99] for Model 2. 
Table 4

Maximum Likelihood Estimates [p-values]: Single and Competing Risks Logit Models

\begin{tabular}{|c|c|c|c|}
\hline Variable & $\begin{array}{c}\text { MODEL } 1 \text { - Single Risk } \\
\text { Dropout vs Continuation }\left(q_{1}\right) \\
{[1]}\end{array}$ & $\begin{array}{c}\text { MODEL 4a - Competing Risks } \\
\text { Dropout for reasons other than } \\
\text { course transfers vs } \\
\text { Continuation } \\
{[2]} \\
\end{array}$ & \begin{tabular}{|c} 
MODEL 4 b - Competing Risks \\
Dropout for reasons of course \\
transfers vs Continuation \\
{$[3]$} \\
\end{tabular} \\
\hline Intercept & $-0.973[0.02]_{* *}^{* *}$ & $-1.676[0.00]_{* *}^{* *}$ & $-2.050[0.00]_{* *}^{* *}$ \\
\hline Time trend & $-0.754[0.00]^{* *}$ & $-0.638[0.00]^{* *}$ & $-1.021[0.00]^{* *}$ \\
\hline 1986 Year Dummy & $0.026[0.74]$ & $-0.085[0.36]$ & $0.291[0.04]^{* *}$ \\
\hline Entry Age $($ Aged $\leq 18)$ & & & \\
\hline Aged $19-21$ & $-0.041[0.65]$ & $0.022[0.84]$ & $-0.224[0.18]$ \\
\hline Aged $>21$ & $0.380[0.06]_{*}^{*}$ & $0.669[0.00]_{*}^{* *}$ & $-0.224[0.18]$ \\
\hline Sex - male & $0.151[0.06]_{*}^{*}$ & $0.181[0.06]^{*}$ & $0.075[0.60]$ \\
\hline British National & $-0.315[0.09]^{*}$ & $-0.083[0.71]$ & $-0.924[0.00]^{* *}$ \\
\hline Non UK fee student & $-0.153[0.53]$ & $0.153[0.57]$ & $-1.099[0.05]^{* *}$ \\
\hline Accommodation (Living at home) & & & \\
\hline Campus & $-0.106[0.46]$ & $-0.115[0.50]$ & $-0.035[0.90]$ \\
\hline 'Other' & $0.190[0.25]$ & $0.281[0.13]$ & $-0.249[0.51]$ \\
\hline School Attended (LEA) & & & \\
\hline Grammar School & $-0.214[0.16]$ & $-0.342[0.07]^{*}$ & $0.061[0.81]$ \\
\hline Independent School & $0.043[0.66]$ & $0.000[1.00]$ & $0.140[0.43]$ \\
\hline College of Further Education & $0.091[0.55]$ & $0.080[0.66]$ & $0.117[0.65]$ \\
\hline 'Other' & $0.016[0.95]$ & $-0.085[0.76]$ & $0.336[0.46]$ \\
\hline Main Entry Qualifications & & & \\
\hline A-Level scores & $-0.033[0.01]^{* *}$ & $-0.035[0.02]^{* *}$ & $-0.020[0.42]$ \\
\hline 'H' scores & $-0.015[0.61]$ & $-0.038[0.27]$ & $0.031[0.56]$ \\
\hline Other 'A'/'AS' Level scores & $-0.006[0.54]$ & $-0.019[0.14]$ & $0.016[0.35]$ \\
\hline Other ' $\mathrm{H}$ ' scores & $-0.075[0.05]^{* *}$ & $-0.050[0.21]$ & $-0.099[0.10]^{*}$ \\
\hline Achieved Top Score & $-0.506[0.00]^{* *}$ & $-0.499[0.00]^{* *}$ & $-0.530[0.01]^{* *}$ \\
\hline Has Maths 'A' Level/Higher & $0.079[0.55]_{* *}$ & $0.150[0.34]_{* *}$ & $-0.052[0.82]$ \\
\hline No favoured subject & $0.804[0.01]^{* *}$ & $0.974[0.00]^{* *}$ & $0.250[0.75]$ \\
\hline One favoured subjects & $-0.007[0.98]$ & $-0.015[0.97]$ & $0.083[0.89]$ \\
\hline Three favoured subjects & $-0.227[0.06]^{*}$ & $-0.146[0.32]$ & $-0.363[0.08]^{*}$ \\
\hline
\end{tabular}


Table 4- Continued

\begin{tabular}{|c|c|c|c|}
\hline Variable & $\begin{array}{c}\text { MODEL } 1 \text { - Single Risk } \\
\text { Dropout vs Continuation }\left(q_{1}\right) \\
{[1]}\end{array}$ & \begin{tabular}{|} 
MODEL 4a - Competing Risks \\
Dropout for reasons other than \\
course transfers vs \\
Continuation \\
{$[2]$} \\
\end{tabular} & $\begin{array}{l}\text { MODEL } 4 \mathrm{~b} \text { - Competing Risks } \\
\text { Dropout for reasons of course } \\
\text { transfers vs Continuation } \\
{[3]}\end{array}$ \\
\hline \multicolumn{4}{|l|}{ Other Entry Quals (A-levels/Highers) } \\
\hline UK university qualifications & $-0.920[0.00]^{* *}$ & $-0.836[0.00]^{* *}$ & $-2.825[0.00]^{* *}$ \\
\hline Other & $-1.588[0.00]^{* *}$ & $-1.538[0.00]^{* *}$ & $-2.825[0.00]^{* *}$ \\
\hline \multicolumn{4}{|l|}{ Parental Social Class (Professional) } \\
\hline Intermediate & $-0.041[0.71]$ & $0.077[0.57]$ & $-0.250[0.17]$ \\
\hline Skilled Non-manual & $0.291[0.06]^{*}$ & $0.470[0.01]^{* *}$ & $-0.094[0.73]$ \\
\hline 'Other' & $0.129[0.30]$ & $0.224[0.15]$ & $-0.086[0.68]$ \\
\hline Father/Guardian is a Doctor & $-0.096[0.50]$ & $0.160[0.33]$ & $-0.700[0.01]^{* *}$ \\
\hline University dummies included & Yes & Yes & Yes \\
\hline Maximised log likelihood value & -2935.48 & -2204.29 & -1077.32 \\
\hline $\begin{array}{l}\text { Proportion who exit into given state during the } \\
\text { early part of the program }\end{array}$ & 0.091 & 0.063 & 0.028 \\
\hline
\end{tabular}

Notes:

1. For classes of dummy variables the default class is indicated in parentheses.

2. ** indicates significance at the $1 \%$ level, * indicates significance at the $5 \%$ level.

3. Because a of lack of enough observations to identify the effects, the model presented in column [3] has two variables entered as a sum. These were on 'Other Entry Qualifications' and the age dummy. 
Figure 1: Estimated medical school coefficients and $95 \%$ confidence intervals - (FE= $\times$ and $R E=\diamond)$

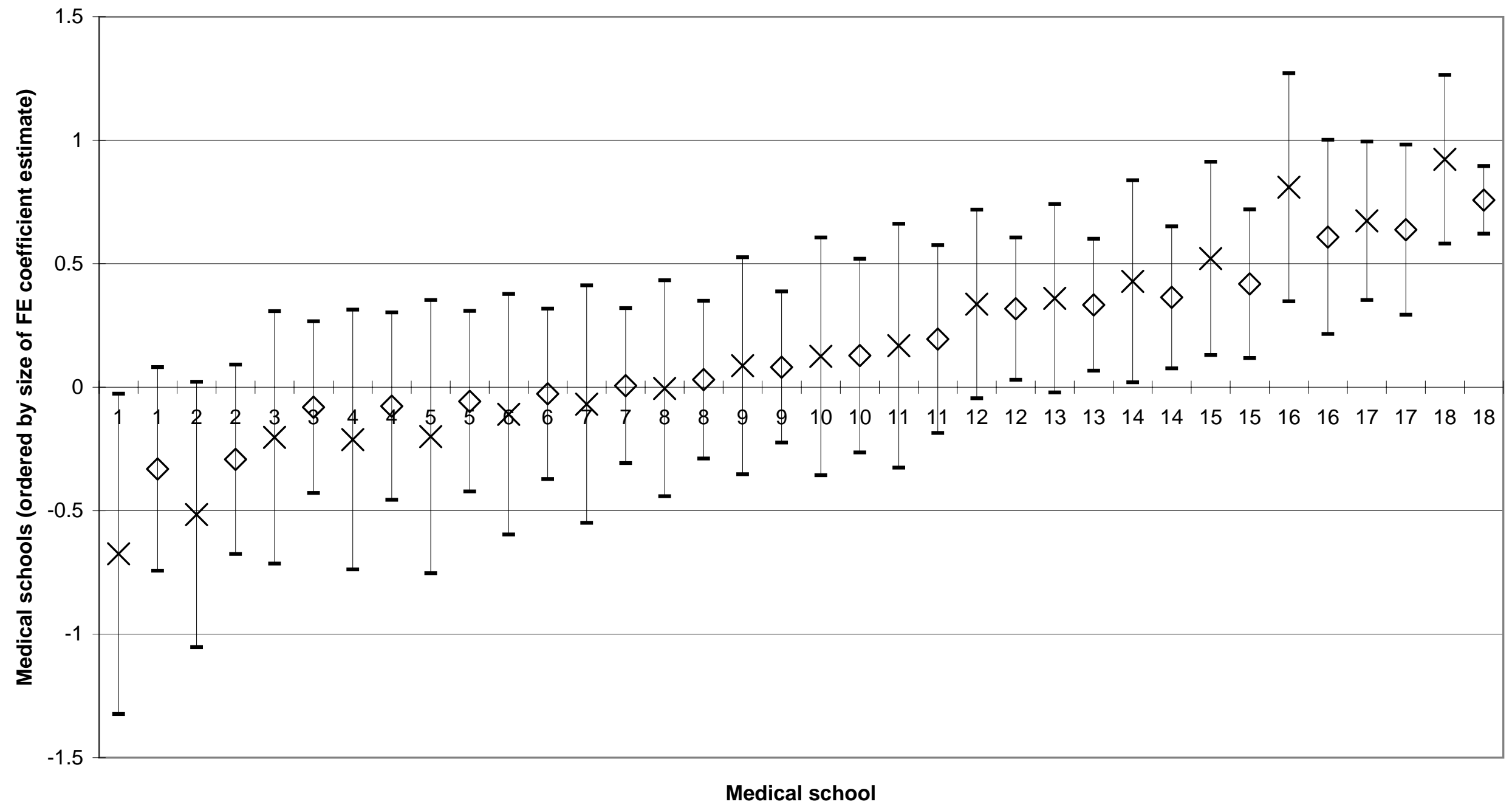

39 